\title{
Optimization of Exenatide plus Detemir Treatment for Morbid Obese Patients with Insulin Dependent Diabetes Resistant to Conventional Treatment. Effect of Exenatide on Patients with Mellitus Diabetes Type 2
}

\author{
Alfonso López Ruiz*, María Ángeles Núñez Sánchez, Noelia Victoria García-Talavera Espín, \\ Amparo Meoro Avilés, Cristina del Peso Gilsanz, Ricardo Soriano Sánchez, \\ María Teresa Gallego García, José Soriano Palao, María Dolores Ortuño, \\ Sacramento Tomás Navarro, Collaborative Groups of the Diabetes and Obesity Unit of the \\ Hospital Reina Sofía \\ Unidad de Diabetes y Obesidad del Área VII Murcia Este, Hospital General Universitario Reina Sofía de Murcia, \\ Murcia, España \\ Email: ${ }^{*}$ alfonsolopezruizmail@gmail.com
}

Received 11 February 2014; revised 28 March 2014; accepted 14 April 2014

Copyright (C 2014 by authors and Scientific Research Publishing Inc.

This work is licensed under the Creative Commons Attribution International License (CC BY). http://creativecommons.org/licenses/by/4.0/

\section{Open Access}

\section{Abstract}

The purpose of this study was to analyze the effects of the treatment with Exenatide joint to insulin detemir. The study was carried out with obese patients with type 2 diabetes mellitus (DM2) and deficient control, despite intensive insulin therapy combined with oral antidiabetics. A longitudinal study was made with 15 patients controlled by the Endocrinology and Nutrition Section of the Reina Sofía University Hospital, Murcia. These patients were treated with Exenatide joint to insulin during 3, 6 and 12 months. Statistically meaningful differences $(p<0.05)$ were observed in the reduction of $\mathrm{HbA1c}$ in the 3 and 6 months treatment groups (initial HbA1c: $9.55 \% \pm 1.086 \%$, weight: $119.94 \mathrm{~kg}$, insulin requirement: $0.71 \mathrm{IU} / \mathrm{kg} /$ day; after 3 months: $\mathrm{HbA1c}: 7.77 \% \pm 1.164 \%$, weight: $98.13 \mathrm{~kg}$, insulin requirement: $0.59 \mathrm{IU} / \mathrm{kg} /$ day; after 6 months: $\mathrm{HbA1c:} 7.21 \%$, weight: $97.93 \mathrm{~kg}$, insulin requirement: $0.55 \mathrm{IU} / \mathrm{kg} /$ day). It was observed that the association of Exenatide and insulin promotes an improvement in several indicators such as weight, body mass index (BMI), systolic pressure (SP), diastolic pressure (DP), triglycerides (TG), cLDL, cHDL and total cholesterol (TC), in patients with diabetes resistant to conventional therapy. However, these improvements were statistically no significant $(p<0.05)$. It is possible to talk of a reduction of cardiovascular risk factors in patients with Exenatide, being thus a suitable option for this kind of individuals. It is

\footnotetext{
"Corresponding author.

How to cite this paper: Ruiz, A.L., Sánchez, M.Á.N., Espín, N.V.G.-T., Avilés, A.M., del Peso Gilsanz, C., Sánchez, R.S., García, M.T.G., Palao, J.S., Ortuño, M.D., Navarro, S.T. and Collaborative Groups of the Diabetes and Obesity Unit of the Hospital Reina Sofía (2014) Optimization of Exenatide plus Detemir Treatment for Morbid Obese Patients with Insulin Dependent Diabetes Resistant to Conventional Treatment. Effect of Exenatide on Patients with Mellitus Diabetes Type 2. Pharmacology \& Pharmacy, 5, 433-443. http://dx.doi.org/10.4236/pp.2014.54053
} 
important to emphasize the fact that our study showed bigger body-weight reductions results after 6 and 12 months, as compared to the researches quoted.

\title{
Keywords
}

\author{
Type 2 Diabetes Mellitus; Rational Use of Drugs; Pharmaceutical Care; Exenatide; Cardiovascular \\ Risk; Physical and Biochemical Parameters
}

\section{Introduction}

Exenatide (Exenatide, from Eli Lilly labs) is an incretin mimetic, a synthetic peptide (a 39 amino-acid peptide amide acid) that is now approved by several countries all around the world (commercialized in the European Union since 2006) for its use as a therapy combined with sulfonylureas, metformin and/or glitazonesin patients with type 2 diabetes mellitus (DM2) in whom an adequate glycemic control has not been achieved through previous oral antidiabetis [1] [2]. Its therapeutic action is basically related to postprandial or fasting glycaemia, considering the following four aspects [3]-[6]:

1) Increase of insulin secretion for $\beta$ cells depending on glucose (reduction of insulin release along to glycaemiadecrease).

2) Inhibition of glucagon secretion, and thus hepatic neoglucogenesis.

3) Slowing down of gastric emptying and, consequently, of glucose consumption passing to blood circulation.

4) Increase of satiety feeling.

According to Diabetes American Society guidelines, Exenatide is indicated as an alternative to insulinic therapy or other third line measures in obese patients with MD2, combined with sulfonylurea or metformin, and/or glytaone, when these options have not achieved adequate glycemic results in maximum doses [1] [7]-[9].

However, according to the Centro Andaluz de Información de Medicamentos (CADIME) [2] and Campoamor [3], Exenatide has a high daily and annual cost (considering its two doses) as compared to the rest of the available oral and insulinic therapeutic options. In the year 2009, the daily cost was of $4.47 €$, the highest prize, which was followed by vildagliptin (2.25€), insulin detemir recharged syring (2.09€), insulin glargine cartridge (2.05€), insulin glargine recharged syringe (2.05€), pioglitazone (2.03€) and sitagliptine (2.00€).

Regarding approved indications, there is nowadays some debate about Exenatide effectiveness, which is under constant research and is the main reason of this study. There is a certain consensus regarding the fact that its administration is associated to a meaningful decrease in glycosylated hemoglobin levels (HbA1c) and body weight [1] [2].

There is also not much scientific information available regarding its use in non-obese patients and in combination with insulin and other kind of oral antidiabetics, as glitazones, as well as regarding its mortality and morbidity and its association with cardiovascular and hepatic risk factors.

Specifically regarding cardiovascular risk associated to mellitus diabetes, there is a controversy nowadays regarding Exenatide, as both favorable [10]-[16] and disfavorable effects on cardiac frequency and arterial pressure have been observed [10] [17] [18].

The purpose of this study is to contribute to the evolutive analysis of Exenatide effects regarding several biochemical and physical indicators, evaluating them in the specific case of adult patients with mellitus diabetes type 2 with a high cardiovascular risk.

\section{Material and Methods}

The study was carried out through several measurements of physical and biochemical parameters of 15 adult individuals with mellitus diabetes type 2 and high cardiovascular risk. The sample was selected through a nonprobabilistic, intentional and incidental type sampling.

A non-experimental, longitudinal, quantitative and prospective study was carried out. It consisted of ambulatory patients with mellitus diabetes type 2 and overweight, ambulatory controlled by the Endocrinology and Nutrition Section of the Reina Sofia University Hospital, Murcia, Spain, in the 2009-2010 period, who having been 
treated with intensive insulin therapy combined with oral hypoglycemic drugs, showed a deficient metabolic control (HbA1c > 7\%) according to 2008 ADA parameters.

A certain number of physical data were collected: weight $(\mathrm{kg})$, height $(\mathrm{cm})$ waist parameter $(\mathrm{cm})$, body mass index (BMI) $\left(\mathrm{Kg} / \mathrm{m}^{2}\right)$, systolic blood pressure (SP) and diastolic blood pressure (DP) in mmHg; as well as biochemical data: HDLc in mg/dl, LDLc (mg/dl), total cholesterol (TC) in mg/dl, triglycerides in mg/dl (TG), glycosylated hemoglobin (HbA1c) in percentages and C-peptide.

Three points of evolutive observation were taken into account: 3, 6 and 12 months. Thus, from the point of view of statistics, it is a design of mixed effects, with a repeated measures factor, the measuring time (pretestposttests), and several factor between individuals (which will be presented later, in relation to their profile).

The treatment included Exenatide and insulin detemir. In addition, its previous treatment was oral antidiabetics like metformin, pioglitazone and quick action sulfonylureas was maintained in order to achieve the goals of maximum control according to the SED's criteria.

In all of the cases, and whenever it was pertinent, information was given regarding: time of consumption, insulin units per day (IU/day) medication concomitant to treatment with Exenatide, basal/prandial percentage of insulin and units of insulin/day. All the patients started the first month with Exenatide $5 \mu \mathrm{g}$ and on the second month they passed to $10 \mu \mathrm{g}$, always twice a day, keeping this same dose during the following months.

In its approved form, Exenatide is available in pre-charged syringes of 5 and $10 \mu \mathrm{g}$ to be administered through subcutaneous injection. It is advisable to begin the treatment administering $5 \mu \mathrm{g} /$ twice/day during 1 month, in order to increase tolerance. It is also recommended to perform the application in the 60 minutes previous to breakfast and dinner, or to the two main meals, separated by at least 6 hours. During the second month, in order to improve glycemic control, the dose must be raised up to $10 \mu \mathrm{g} /$ twice/day, following the recommendations of administration already exposed [1] [2].

The criteria sustained by the American Diabetes Association (ADA) will be considered as those of optimum control criteria.

All the analysis were carried out with the software SPSS version 15.0 for Windows, considering level of meaning $\mathrm{p}<0.05$.

\section{Results}

The general features of the group of patients with type 2 diabetes in a combined treatment of Exenatide and detemir was the following: mean age $55.60 \pm 9.093$ years, $60 \%$ women, $40 \%$ men, initial mean weight $119.94 \mathrm{~kg} \pm$ $13.86 \mathrm{~kg}$, initial BMI $40.60 \pm 6.54 \mathrm{~kg} / \mathrm{m}^{2}$, mean length of the treatment $5.60 \pm 2.971$ months and mean evolution of diabetes 9 years.

No statistically significant differences $(\mathrm{p}<0.05)$ were found between the groups undergoing 3 months treatment or 6 months treatment regarding the factors sex, age and initial BMI, that considering the final and intermediate instances for the second group (the moment of three months).

In Table 1 the basal and subsequent average conditions of all the biochemical indicators evaluated in the study, as well as those of the insulin requirements. This average presentation was only carried out for the 3 and 6 months groups of patients, since the 12 months group consists of only two individuals (its description was made case by case).

The basal conditions of the selected sample of diabetics show non-optimal parameters of metabolic control according to the criteria adopted for this study.

The group under a 3 months treatment combined with Exenatide showed statistically meaningful differences in the parameterHbA1c: $9.55 \% \pm 1.086 \%$ in the initial moment, and $7.77 \% \pm 1164 \%$ at the end.

The group that underwent a 6 months Exenatide treatment also showed statistically significant differences in HbA1c: $8.71 \% \pm 0.932 \%$ in the initial moment, and $7.21 \% \pm 0.644 \%$ in the final moment.

In relation to this, statistically significant differences $(\mathrm{p}<0.05)$ were also found when observing jointly the initial moment, the 3 months and the 6 months moment $\left(F_{2.17}=5.839 ; p=0.012\right)$. In this case, the Duncan test made it possible to identify two homogeneous subgroups: initial and 3 months moment on one side (mean number $8.71 \%$ and $8.28 \%$, respectively) and 6 months moment on the other side (mean $7.21 \%$ ). Therefore, it was observed that the most significant decrease on glycosylated hemoglobin was after 6 months long Exenatide plus insulin detemir treatment.

Regarding the cases of people undergoing a 12 months long treatment with Exenatide, no statistically signifi- 
cant differences were found $(\mathrm{p}>0.05)$ in any of the physical or biochemical parameters, corresponding with initial HbA1c $8.70 \% \pm 1.556 \%, 7.90 \% \pm 1.272 \%$ three months later, $7.30 \% \pm 0.849 \%$ after six months, and $7.00 \%$ $\pm 0.707 \% 12$ months later. It was possible to observe that HbA1c is lower (maximum decrease) in the 12 months long treatment group.

As to the groups undergoing 3, 6, and 12 months of treatment no statistically significant differences were found ( $p>0.05$ ) regarding the initial BMI although a decrease tendency in the BMI was noted.

No increase of the side effects of the drugs (Exenatide and insulin detemir) was observed after combining them, nor either any interaction between them.

In Figure 1 the levels of HbA1c, body weight and IU/kg/day for each group of treatment have been displayed evolutively.

The evolution of the mentioned indicators (HbA1c, body weight and IU/kg/day) was examined globally. For this reason, the whole number of patients was taken into account at each control moment $(0,3,6$ and 12 months).

It is possible thus to notice that in all of the groups undergoing an Exenatide plus insulin detemir treatment a statistically significant decrease of HbA1c is observed, being possible to deduce a favorable effect of Exenatide plus insulin detemir in the profile of patients with diabesity after 3, 6 and 12 months.

A statistically no significant decrease $(p>0.05)$ was noticed in weight $\left(F_{3,26}=0.457 ; p=0.715\right)$ as well as in insulin requirements (IU/kg/day) $\left(\mathrm{F}_{3,26}=0.212 ; \mathrm{p}=0.887\right)$. In both cases, the Duncan Test showed ahomogeneous subgroup, according to the average values presented in Figure 1.

Table 1. Basal and subsequent average conditions for the physical, biochemical and treatment parameters for each group treated at 3 and 6 months, and for each case in the 12 months treatment group.

\begin{tabular}{|c|c|c|c|c|c|}
\hline \multicolumn{6}{|c|}{3 OR 6 MONTHS TREATMENT GROUPS (AVERAGE FIGURES) } \\
\hline \multirow{2}{*}{ Parameter biochemical } & \multicolumn{2}{|c|}{3 months } & \multicolumn{3}{|c|}{6 months } \\
\hline & Initial & Final & Initial & 3 months & 6 months \\
\hline Weight (kg) & $102.92 ; \mathrm{TD}=31.537$ & $98.13 ; \mathrm{TD}=28.537$ & $\begin{array}{c}105.11 ; \\
\text { TD }=13.080\end{array}$ & - & 97.93; TD = 13.631 \\
\hline BMI $\left(\mathrm{kg} / \mathrm{m}^{2}\right)$ & $41.17 ; \mathrm{TD}=12.222$ & $39.17 ; \mathrm{TD}=11.514$ & $\begin{array}{c}37.00 ; \\
\mathrm{TD}=3.916\end{array}$ & $\begin{array}{c}35.40 \\
\mathrm{TD}=4.775\end{array}$ & $34.50 ; \mathrm{TD}=4.183$ \\
\hline Total cholesterol (mg/dl) & $247.60 ; \mathrm{TD}=47.210$ & $\begin{array}{c}202.00 ; \\
\mathrm{TD}=34.322\end{array}$ & $\begin{array}{c}161.57 ; \\
\text { TD }=29.142\end{array}$ & - & $147.57 ; \mathrm{TD}=14.270$ \\
\hline cLDL (mg/dl) & $148.80 ; \mathrm{TD}=46.019$ & $\begin{array}{c}127.00 \\
\mathrm{TD}=23.537\end{array}$ & $\begin{array}{c}88.71 ; \\
\text { TD }=23.719\end{array}$ & - & $\begin{array}{c}\text { 73.86; } \\
\text { TD = 19.912 }\end{array}$ \\
\hline cHDL (mg/dl) & $\begin{array}{c}\text { Woman: } 50.50 ; \\
\text { TD }=6.364 \\
\text { Man: } 52.50 ; \text { TD }=4.950\end{array}$ & $\begin{array}{c}\text { Woman: 54.50; } \\
\text { TD = 3.536 } \\
\text { Man: 51.50; } \\
\text { TD = } 0.707\end{array}$ & $\begin{array}{c}\text { Woman: 45.33; } \\
\begin{array}{c}\text { TD = } 6.807 \\
\text { Man: } 44.00 ; \\
\text { TD = } 12.780\end{array}\end{array}$ & - & $\begin{array}{c}\text { Woman: } 45.67 ; \\
\text { TD }=7.234 \\
\text { Man: } 48.25 ; \text { TD }=9.743\end{array}$ \\
\hline TG (mg/dl) & $293.00, \mathrm{TD}=277.716$ & $\begin{array}{c}145.83 ; \\
\mathrm{TD}=54.168\end{array}$ & $\begin{array}{c}185.57 \\
\mathrm{TD}=66.960\end{array}$ & - & 121.86; $\mathrm{TD}=43.575$ \\
\hline TAS (mm Hg) & 157.33; TD = 20.849 & $\begin{array}{c}137.00 \\
\mathrm{TD}=10.733\end{array}$ & $\begin{array}{c}132.86 \\
\text { TD }=19.12\end{array}$ & - & $127.57 ; \mathrm{TD}=8.243$ \\
\hline TAD (mm Hg) & $89.17 ; \mathrm{TD}=12.368$ & $75.83 ; \mathrm{TD}=10.048$ & $\begin{array}{c}79.00 \\
\mathrm{TD}=9.730\end{array}$ & - & $\begin{array}{c}77.57 \\
\mathrm{TD}=5.318\end{array}$ \\
\hline HbA1c (\%) & $\begin{array}{c}9.55 \\
\mathrm{TD}=1.086\end{array}$ & $7.77 ; \mathrm{TD}=1.164$ & $\begin{array}{c}8.71 ; \\
\mathrm{TD}=0.932\end{array}$ & - & $\begin{array}{c}7.21 \\
\mathrm{TD}=0.644\end{array}$ \\
\hline $\mathrm{UI}$ & $85.50 ; \mathrm{TD}=126.835$ & $52.17 ; \mathrm{TD}=60.334$ & $61.28 ; \mathrm{TD}=19.872$ & - & $53.43 ; \mathrm{TD}=16.851$ \\
\hline UI/kg/día & $0.71 ; \mathrm{TD}=0.872$ & $0.51 ; \mathrm{TD}=0.511$ & $0.59 ; \mathrm{TD}=0.191$ & - & $0.55 ; \mathrm{TD}=0.168$ \\
\hline
\end{tabular}




\section{Weight (kg)}
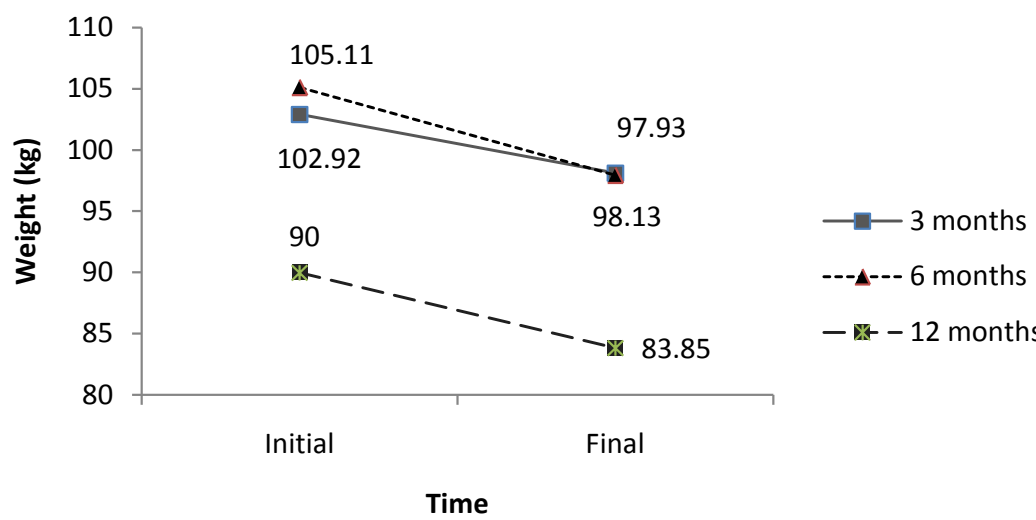

---1--- 6 months

$-x-12$ months

(a)

IU (IU/kg/day)

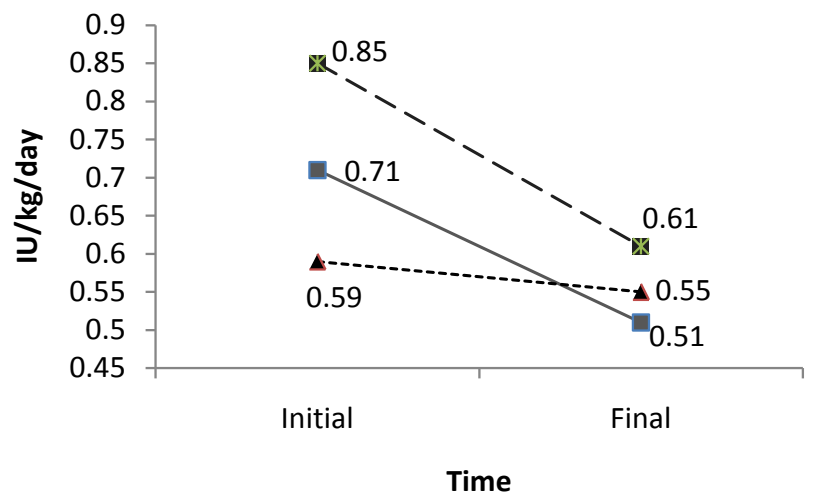

(b)

HbA1c (\%)

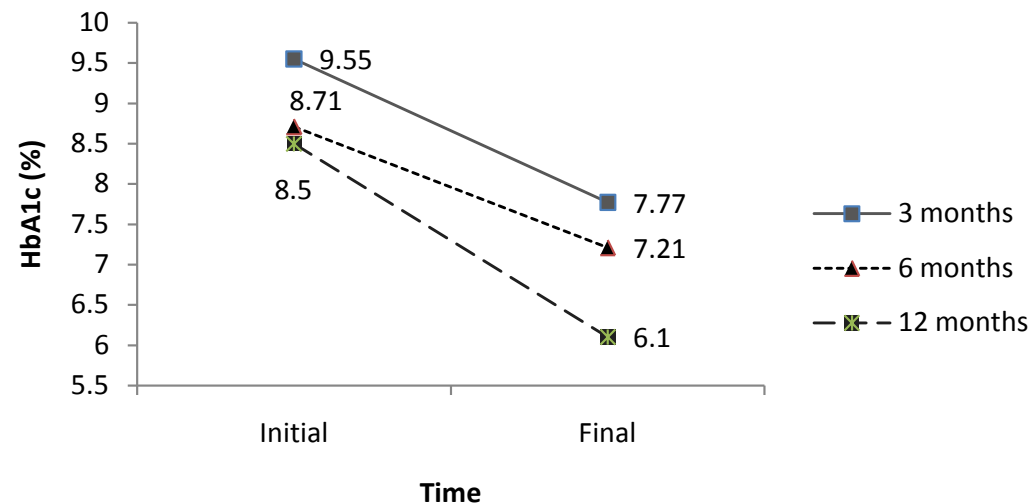

(c)

Figure 1. (a) Weight; (b) Insulin units and (c) HbA1c evolution after 3, 6 or 12 months of treatment.

Regarding glycosylated hemoglobin, statistically significant differences $(\mathrm{p}<0.05)\left(\mathrm{F}_{3,36}=8.611 ; \mathrm{p}=0.000\right)$ were found, placing the initial values, as well as the values after 6 and 12 months, in different homogeneous subgroups. 
HbA1c values get significantly reduce already at the first control point (that is, 3 months), where the point of convergence towards decrease of this indicated is found.

The most important matter issue, then, lays in the detection of a statistically significant decrease in the levels of glycosylated hemoglobin, which is associated to non-significant tendencies of reduction in weight and UI/kg/day. Also in the observation of an adequate effectiveness of Exenatide plus insulin detemir, regarding glycaemia control and other factors of cardiovascular risk, as well as a reduction in weight. Even thought, it remains without thorough explanation the sensitizer effect of Exenatide on this group.

\section{Discussion}

The significant effects of treatment with Exenatide on patients with mellitus diabetes type 2 were observed for the parameter HbA1c3 months $(-1.78 \%)$ and 6 months $(-1.50 \%)$ after the treatment start. Statistically significant differences $(\mathrm{p}<0.05)$ came up in the intermediate 3 months treatment. The 12 months long treatment did not result in significant differences regarding glycosylated hemoglobin, maybe due to the constitution of a nonrandomized sample, consisting in only two patients, although a lower mean values were observed if compared to the other groups. What was observed, though, were average values lower than those of earlier groups.

The above said significant effect was shown by all the patients, regardless of sex, age and initial BMI.

The results of this study regarding glycosylated hemoglobin reduction, are consistent with those of most of current investigation. Thus, comparing the effectiveness of Exenatide plus insulin with that of sitagliptin [2] [19]-[28], although not matching adequate glycemic controls according to SED, has proved that Exenetide has a sensitizer effect on insulin.

This can also be justified by the reduction of insulin needs, an aspect also associated to weight loss, but it has to be considered no significant decrease $(\mathrm{p}<0.05)$ regarding the basal values displayed in Table 1.

It is also worth noting, as it is one the purposes of this study, that a significant reduction of Exenatide regarding biochemical parameters associated to cardiovascular risk was noted in none of the treatment groups: SP, DP, TG, cLDL, cHDL and total cholesterol.

This is very important since, although evolutive tendencies towards adequate parameter values have been noticed, there were not significant $(p>0.05)$ in any of the groups of treatment (in relation to the basal values displayed in Table 2), and having observed an improvement on the glycemic control. These results match with several studies carried out in practically the same time range [10] [29]-[32].

It is interesting to compare these results to those of a similar and recent study by Buse et al. [33]. In the latter, the authors meant to examine whether administering Exenatide twice a day may help reduce the levels of HbA1c, considering its application altogether with insulin glargine, and comparing the results with those of a placebo group. Parameters such as body weight, waist circumference, insulin dose, glycemic profiles, unfavorable effects and cardiovascular parameters (SP and DP) were taken into account.

Similarities between this study and the above mentioned are particularly clear in the statistically significant reduction of the levels of HbA1c, being of 1.74\% in Buse et al.' study [33], in the period of 30 weeks (approximately 7 months and a half), and of $1.78 \%$ in the group that underwent a 3 months long treatment, $1.50 \%$ in the6 months long treatment, and of $1.70 \%$ in the group that underwent a 12 months long treatment, according to our study.

The first differences refer to methodological aspects, to administering different insulin in combination (glarginevs. determir) and to evaluating different time treatments in our study. The main differences are associated to the discovery of statistically significant differences for some cardiovascular parameters in the study carried out by Buse et al. [33], such as the SP. These differences were also found in the body weight. In both cases a decrease of values was observed.

In both studies favorable effects were proved, pointing to the possibility of reducing glycaemia and cardiovascular risk though administration of Exenatide plus insulin.

On the other hand, comparing with other studies such as those by Kolterman et al. [34], Arnolds [35], there is also concordancein showing a significant reduction of glucose levels: In the first of these studies, fasting and postprandial measurements were taken during a maximum period of 8 hours. In the second one, measurements were postprandial, with a maximum of two months, although it is necessary to bear in mind that the medication regime was also different, employing triple therapies of Exenatide + insulin glargine + metformin or Exenatide + insulin glargin + sitagliptin. Regarding this study it is also important to bear in mind that, in contrast with 
Table 2. 12 months treatment group.

\begin{tabular}{ccccc} 
& \multicolumn{2}{c}{ Case 1} & & Case 2 \\
\cline { 2 - 4 } & Initial & Final & Initial & Final \\
\hline Weigth (kg) & 80.00 & 75.70 & 100.00 & 92.00 \\
BMI (kg/m²) & 37.00 & 34.00 & 40.00 & 153.00 \\
Total & 212.00 & 195.00 & 162.00 & 93.00 \\
cholesterol (mg/dl) & 140.00 & 118.00 & 100.00 & 43.00 \\
cLDL (mg/dl) & - & - & 39.00 & 150.00 \\
cHDL (mg/dl) & 136.00 & 125.00 & 170.00 & 160.00 \\
TG (mg/dl) & 176.00 & 165.00 & 163.00 & 68.00 \\
TAS (mm Hg) & 75.00 & 82.00 & 70.00 & 7.50 \\
TAD (mm Hg) & 7.60 & 6.50 & 9.80 & 32.00 \\
HbA1c (\%) & 96.00 & 66.00 & 50.00 & 0.35 \\
IU & 1.20 & 0.87 & 0.50 & \\
\hline IU/kg/day & & & & \\
\hline
\end{tabular}

ours, optimum levels $\mathrm{HbA1c}$, fixed in $\leq 7 \%$ according to accepted parameters, have been reached.

Regarding the study by Yoon et al. [36], considering a methodology similar to the one applied in our study (different time periods, a regime of Exenatide + insulin), higher meanHbA1c reductions were found, for 0 - 6 months period $(-0.19 \%$ en in our case, as compared to $-0.66 \%)$ as well as for the $6-12$ months $(-0.02 \%$ in our case as compared to $-0.55 \%$ ). The opposite was observed regarding the body weight for the $0-6$ months period ( $-4 \mathrm{~kg}$ in our study as compared to $-2.4 \mathrm{~kg}$ ) as well as for the $6-12$ months period $(-14 \mathrm{~kg}$ in our study as compared to $-4.3 \mathrm{~kg}$ ), noting a higher reduction, possibly due to a high basal average BMI, of around $39 \mathrm{~kg} / \mathrm{m}^{2}$. Significant reductions of the daily total dose of insulin during those periods ( $-18.0 \mathrm{U}$ and $-14.8 \mathrm{U}$, respectively) were found, and the use of detemir instead of glargine.

It is also worth noting the fact that higher body weight reductions after 6 and 12 months were observed, as compared to those observed in the mentioned investigations, because our patients had a higher BMI and insulin was combined with detemir instead of with glargine.

In relation to the study by Sheffield et al. [37], who evaluated as well the effectiveness and safety of Exenatide as a therapy combined with insulinization, they found a reduction of $-0.87 \%$ in HbA1c and an average weight loss of $-5.2 \mathrm{~kg}$, among other results, during a period of 12 months. Comparing with our study, we noticed that in the latter, a reduction of HbA1cof $-0.21 \%$, and a mean body weight loss of $-18 \mathrm{~kg}$ was observed. Lower reductions de HbA1c and higher reductions of body weight were found.

These variations agree, however, with those found by Nayak et al. [38] in their study, which was carried out in similar way to ours, measuring the levels ofHbA1c, weight, BMI and several biochemical indicators at three different control points: 3, 6 and 12 months. Thus, although no significant changes regarding HbA1c were found (although they did observe a tendency towards reduction), regarding weight the average loss was of $10.7 \mathrm{~kg}$ and $12.8 \mathrm{~kg}$ at 6 and 12 months, respectively. Significant reductions in the dose of insulin were observed as well, going down from an average of 144 IU/day at the beginning to a 51 IU/day and 55 IU/day 6 months and 12 months later, respectively).

We can talk of a comparative effectiveness not inferior to that of insulin and similar to that sitagliptin. Its administration is associated to high index of desertion of treatment due to the unfavorable effects: $8 \%$ as compared to $3 \%$ of the placebo and $1 \%$ of the insulin [2]. Among the main unfavorable effects we can mention [1] [2] [39]-[43]:

- Nausea (45\% - 51\%).

- Vomiting (12\% - 14\%). 
- Diarrhea (9\% - 17\%).

- Hypoglycemic episode (28\% - 36\%), combined with sulfonylureas.

- Acute pancreatitis (89 cases in the European Union in the period 2006-2007).

In this respect, although unfavorable effects depend on the continuity of the treatment, as well as on the combined therapy applied, it is certain that faced to the apparent advantages of reducing HbA1c and body weight, the low risk of hypoglycemia (except in combination with sulfonylurea), lowering the blood pressure and a potential protecting effect on $\beta$ cells; the disadvantages are: its administration by injection, frequent digestive system side-effects, high cost, low experience in the treatment, creation of antibodies and possible interaction with other medication, due to slow gastric vacating.

Therefore, it is possible to conclude that the association of Exenatide with insulin detemir promotes and improvement in controlling certain indicators such as glycosylated hemoglobin, weight, BMI, SP, DP, TG, LDL, HDL and total cholesterol in morbid obese patients with diabetes resistant to conventional therapy; associated with a sensitizer effect of Exenatide on the combination of intensive insulin therapy with oral hypoglycemic. Tendency to reducing factors of cardiovascular risk together with optimization of glycosylated hemoglobin and weight loss, point to Exenatide + detemir + metformin + pioglitazone as the suitable combination for this profile of individuals with severe diabesity on whom conventional therapy has failed. This leads to the daily cost of the treatment for the diabetic patient going down to approximately half of the cost of the treatment with slow insulin plus oral antidiabetics and the use of hypolipidemics.

\section{Conclusion}

These improvements were statistically no significant $(\mathrm{p}<0.05)$. It is possible to talk of a reduction of cardiovascular risk factors in patients with Exenatide, being thus a suitable option for this kind of individuals. It is important to emphasize the fact that our study showed bigger body-weight reductions results after 6 and 12 months, as compared to the researches quoted.

\section{Acknowledgements}

The authors would like to thank the members of the Area VII-East Murcia Diabetes Unit participated in this study. Hospital: Dr. J. Soriano Palao (Internal Medicine), Dr. R. Soriano Sánchez, Dr. A. MeoroAvilés, Dr. C. del Peso, Dr. M.T. Gallego García, M.C. Lozano Gomariz (Endocrinology), C. Gutiérrez García, S. Tomas Navarro (Diabetes Educator), Dr. I. Selles, (Ophthalmology), Dr. J. Cabezuelo Romero (Nephrology), Dr. I. Marín (Cardiology), Dr. M.L. Martínez Navarro (Neurology), Dr. J Rodado (Psychiatry), Dr. J García Medina (Vascular Radiology), Dr. C Sánchez Cañizares (Urgencies), Dr. E Buendía Pérez (General Surgery), MB Guillermo Vila (Diabetic Foot Nurse), A Cavaría (Podiatrist), Dr. MJ Avilés (Neumology), Dr. C Sánchez Álvarez, M Nicolás Hernández, AI ZomeñoRos, NV García-Talavera Espín, MB Gómez Sánchez, T MonederoSaiz (Nutrition Unit), Dra. MT Antequera Lardón (Pharmacia), MA Nuñez Sánchez (Biochemistry), JM Guirao Sastre (Quality Unit), F San Eustaquio Tudanca (Clinical Documentation). Primary Care: Dr. M.A. Muñoz Tomás, J.C. Martínez Alburquerque (Vistabella), Dr. J. Brotons Román, H. Romero López-Reinoso (Infante), P. García Ortín (Infante-B ${ }^{\circ}$ Progreso), M.R. Gómez Montiel (Beniajám), J. Alcántara Nicolás (Santomera), Dr. P. Villalba Martín, C. Saura García (Puente Tocinos), Dr. M. A. Cervantes Cuesta, P. Brocal Ibáñez (El Carmen), Dr. A. Villalobos Templado, J.L. Gea Martínez, Dr. M.A. Rodríguez Sánchez, P. García Ortín (Alquerías), Dra. M.J.Delgado Aroca, J.M. Olivares (Monteagudo), M.J. Campillo Fernández (Alquerías-Zeneta), Dr. S. Pérez García-Ripoll, P. Abdón Martínez Robles (Llano de Brujas-Casillas).

\section{References}

[1] National Health Service (NHS) (2007) Exenatide. New Drug Evaluation, 84.

[2] Centro Andaluz de Información de Medicamentos (CADIME) (2009) Exenatida (DCI). Ficha de Novedad Terapéutica 2.

[3] Campoamor, F. (2008) Exenatida en la diabetes mellitus tipo 2. Comisión de Evaluación de Medicamentos, Islas Baleares.

[4] Verzegnassi, F. and Chinello, M. (2010) Exenatide in Type 2 Diabetes. Lancet, 376, 1052-1053. http://dx.doi.org/10.1016/S0140-6736(10)61485-7 
[5] Peters, A. (2010) Incretin-Based Therapies: Review of Current Clinical Trial Data. American Journal of Medicine, 123, S28-S37. http://dx.doi.org/10.1016/j.amjmed.2009.12.007

[6] Wajcberg, E. and Tavaria, A. (2009) Exenatide: Clinical Aspects of the First Incretin-Mimetic for the Treatment of Type 2 Diabetes Mellitus. Expert Opinion on Pharmacotherapy, 10, 135-142. http://dx.doi.org/10.1517/14656560802611832

[7] Segal, J.B., Dy, S.M., Millman, E.A., Herbert, R., Bass, E.B. and Wu, A. (2007) Diffusion into Use of Exenatide for Glucose Control in Diabetes Mellitus: A Retrospective Cohort Study of a New Therapy. Clinical Therapeutics, 29, 1784-1794. http://dx.doi.org/10.1016/j.clinthera.2007.08.021

[8] Philippe, J. (2009) Role and Indication of GLP-1 Analogues in the Treatment of Type 2 Diabetes. Revue Médicale Suisse, 5, 1260-1262, 1264-1265.

[9] Reuter, H. and Erdmann, E. (2007) Exenatide-An Incretin-Mimetic Agent for the Treatment of Type 2 Diabetes Mellitus. Deutsche Medizinische Wochenschrift, 132, 571-574. http://dx.doi.org/10.1055/s-2007-970380

[10] Gill, A., Hoogwerf, B.J., Burger, J., Bruce, S., Macconell, L., Yan, P., et al. (2010) Effect of Exenatide on Heart Rate and Blood Pressure in Subjects with Type 2 Diabetes Mellitus: A Double-Blind, Placebo-Controlled, Randomized Pilot Study. Cardiovascular Diabetology, 9, 6. http://dx.doi.org/10.1186/1475-2840-9-6

[11] Moretto, T.J., Milton, D.R., Ridge, T.D., Macconell, L.A., Okerson, T., Wolka, A.M., et al. (2008) Efficacy and Tolerability of Exenatidemonotherapy over 24 Weeks in Antidiabetic Drug-Naive Patients with Type 2 Diabetes: A Randomized, Double-Blind, Placebo-Controlled, Parallel-Group Study. Clinical Therapeutics, 30, 1448-1460. http://dx.doi.org/10.1016/j.clinthera.2008.08.006

[12] Klonoff, D.C., Buse, J.B., Nielsen, L.L., Guan, X., Bowlus, C.L., Holcombe, J.H., et al. (2008) Exenatide Effects on Diabetes, Obesity, Cardiovascular Risk Factors and Hepatic Biomarkers in Patients with Type 2 Diabetes Treated for at Least 3 Years. Current Medical Research and Opinion, 24, 275-286.

[13] Drucker, D.J., Buse, J.B., Taylor, K., Kendall, D.M., Trautmann, M., Zhuang, D., DURATION-1 Study Group, et al. (2008) Exenatide Once Weekly versus Twice Daily for the Treatment of Type 2 Diabetes: A Randomised, Open-Label, Non-Inferiority Study. Lancet, 372, 1240-1250. http://dx.doi.org/10.1016/S0140-6736(08)61206-4

[14] Okerson, T., Yan, P., Stonehouse, A., Brodows, R. and Bhole, D. (2008) Exenatide Improved Systolic Blood Pressure Compared to Insulin or Placebo in Patients with Type 2 Diabetes. Diabetologia, 51, S350.

[15] Bergenstal, R., Kim, T., Yan, P., Darsow, T., Walsh, B., Okerson, T., et al. (2009) Exenatide Once Weekly Improved Cardiometabolic Risk Factors in Subjects with Type 2 Diabetes during One Year of Treatment. Diabetes, 58, A43.

[16] Bhushan, R., Elkind-Hirsch, K.E., Bhushan, M., Butler, W.J., Duncan, K. and Marrioneaux, O. (2009) Improved Glycemic Control and Reduction of Cardiometabolic Risk Factors in Subjects with Type 2 Diabetes and Metabolic Syndrome Treated with Exenatide in a Clinical Practice Setting. Diabetes Technology \& Therapeutics, 11, 353-359. http://dx.doi.org/10.1089/dia.2008.0090

[17] Kothare, P.A., Linnebjerg, H., Isaka, Y., Uenaka, K., Yamamura, A., Yeo, K.P., de la Peña, A., Teng, C.H., Mace, K., Fineman, M., Shigeta, H., Sakata, Y. and Irie, S. (2008) Pharmacokinetics, Pharmacodynamics, Tolerability, and Safety of Exenatide in Japanese Patients with Type 2 Diabetes Mellitus. Journal of Clinical Pharmacology, 48, 1389-1399. http://dx.doi.org/10.1177/0091270008323750

[18] Linnebjerg, H., Kothare, P., Park, S., Mace, K. and Mitchell, M. (2009) The Effect of Exenatide on Lisinopril Pharmacodynamics and Pharmacokinetics in Patients with Hypertension. International Journal of Clinical Pharmacology and Therapeutics, 47, 651-658. http://dx.doi.org/10.5414/CPP47651

[19] Menéndez Torre, E., Lafita Tejedor, J., Artola Menéndez, S., Millán Núñez-Cortés, J., Alonso García, Á., Puig Domingo, M., García Solans, J.R., Álvarez Guisasola, F., García Alegría, J., Mediavilla Bravo, J., Fernández-Santos, C.M. and Romero González, R. (2010) Recomendaciones para el tratamiento farmacológico de la hiperglucemia en la diabetes tipo 2. Avances en Diabetología, 26, 331-338. http://dx.doi.org/10.1016/S1134-3230(10)65006-5

[20] Svec, F. (2010) Incretin Physiology and Its Role in Type 2 Diabetes Mellitus. Journal of the American Osteopathic Association, 110, eS20-eS24.

[21] Sudhakaran, C., Fathima, M., Anjana, R.M., Unnikrishnan, R.I. and Mohan, V. (2010) Effectiveness of Exenatide in Asian Indians in a Clinical Care Setting. Diabetes Technology \& Therapeutics, 12, 613-618. http://dx.doi.org/10.1089/dia.2010.0033

[22] Diamant, M., Van Gaal, L., Stranks, S., Northrup, J., Cao, D., Taylor, K. and Trautmann, M. (2010) Once Weekly Exenatide Compared with Insulin Glargine Titrated to Target in Patients with Type 2 Diabetes (DURATION-3): An Open-Label Randomised Trial. Lancet, 375, 2234-2243. http://dx.doi.org/10.1016/S0140-6736(10)60406-0

[23] Bergenstal, R.M., Wysham, C., Macconell, L., Malloy, J., Walsh, B., Yan, P., Wilhelm, K., Malone, J., Porter, L.E. and DURATION-2 Study Group (2010) Efficacy and Safety of Exenatide Once Weekly versus Sitagliptin or Pioglitazone 
as an Adjunct to Metformin for Treatment of Type 2 Diabetes (DURATION-2): A Randomised Trial. Lancet, 376, 431-439. http://dx.doi.org/10.1016/S0140-6736(10)60590-9

[24] Blevins, T., Han, J., Nicewarner, D., Chen, S., Oliveira, J.H. and Aronoff, S. (2010) Exenatide Is Non-Inferior to Insulin in Reducing HbA1c: An Integrated Analysis of 1423 Patients with Type 2 Diabetes. Postgraduate Medicine, 122, 118-128. http://dx.doi.org/10.3810/pgm.2010.05.2149

[25] Natarajan, B., Edavalath, M., Davies, J., Jenkins, L., Marshall-Richards, N., Evans, D., Price, D.E. and Stephens, J.W. (2010) Clinical Experience with Exenatide in a Routine Secondary Care Diabetes Clinic. Primary Care Diabetes, 4, 57-60. http://dx.doi.org/10.1016/j.pcd.2009.11.001

[26] Yoon, N.M., Cavaghan, M.K., Brunelle, R.L. and Roach, P. (2009) Exenatide Added to Insulin Therapy: A Retrospective Review of Clinical Practice over Two Years in an Academic Endocrinology Outpatient Setting. Clinical Therapeutics, 31, 1511-1523. http://dx.doi.org/10.1016/j.clinthera.2009.07.021

[27] Drucker, D.J., Buse, J.B., Taylor, K., Kendall, D.M., Trautmann, M., Zhuang, D., Porter, L. and DURATION-1 Study Group (2008) Exenatide Once Weekly versus Twice Daily for the Treatment of Type 2 Diabetes: A Randomised, OpenLabel, Non-Inferiority Study. Lancet, 372, 1240-1250. http://dx.doi.org/10.1016/S0140-6736(08)61206-4

[28] Forti, A., Garcia, E.G., Yu, M.B., Jimenez, M.C., Brodows, R.G. and Oliveira, J.H. (2008) Efficacy and Safety of Exenatide Administered before the Two Largest Daily Meals of Latin American Patients with Type 2 Diabetes. Current Medical Research and Opinion, 24, 2437-2447. http://dx.doi.org/10.1185/03007990802282398

[29] Nyström, T., Gutniak, M.K., Zhang, Q., Zhang, F., Holst, J.J., Ahrén, B. and Sjöholm, Å. (2004) Effects of GlucagonLike Peptide-1 on Endothelial Function in Type 2 Diabetes Patients with Stable Coronary Artery Disease. American Journal of Physiology-Endocrinology and Metabolism, 287, E1209-E1215. http://dx.doi.org/10.1152/ajpendo.00237.2004

[30] Thrainsdottir, I., Malmberg, K., Olsson, A., Gutniak, M. and Rydén, L. (2004) Initial Experience with GLP-1 Treatment on Metabolic Control and Myocardial Function in Patients with Type 2 Diabetes Mellitus and Heart Failure. Diabetes and Vascular Disease Research, 1, 40-43. http://dx.doi.org/10.3132/dvdr.2004.005

[31] Sokos, G.G., Nikolaidis, L.A., Mankad, S., Elahi, D. and Shannon, R.P. (2006) Glucagon-Like Peptide-1 Infusion Improves Left Ventricular Ejection Fraction and Functional Status in Patients with Chronic Heart Failure. Journal of Cardiac Failure, 12, 694-699. http://dx.doi.org/10.1016/j.cardfail.2006.08.211

[32] Bunck, M.C., Diamant, M., Eliasson, B., Cornér, A., Shaginian, R.M., Heine, R.J., et al. (2010) Exenatide Affects Circulating Cardiovascular Risk Biomarkers Independently of Changes in Body Composition. Diabetes Care, 33, 17341737. http://dx.doi.org/10.2337/dc09-2361

[33] Buse, J.B., Bergenstal, R.M., Glass, L.C., Heilmann, C.R., Lewis, M.S., Kwan, A.Y., Hoogwerf, B.J. and Rosenstock, J. (2010) Use of Twice-Daily Exenatide in Basal Insulin-Treated Patients with Type 2 Diabetes: A Randomized, Controlled Trial. Annals of Internal Medicine, 154, 1-12.

[34] Kolterman, O.G., Buse, J.B., Fineman, M.S., Gaines, E., Heintz, S., Bicsak, T.A., Taylor, K., Kim, D., Aisporna, M., Wang, Y. and Baron, A.D. (2003) Synthetic Exendin-4 (Exenatide) Significantly Reduces Postprandial and Fasting Plasma Glucose in Subjects with Type 2 Diabetes. Journal of Clinical Endocrinology \& Metabolism, 88, 3082-3089. http://dx.doi.org/10.1210/jc.2002-021545

[35] Arnolds, S., Dellweg, S., Clair, J., Dain, M.P., Nauck, M.A., Rave, K. and Kapitza, C. (2010) Further Improvement in Postprandial Glucose Control with Addition of Exenatide or Sitagliptin to Combination Therapy with Insulin Glargine and Metformin: A Proof-of-Concept Study. Diabetes Care, 33, 1509-1515. http://dx.doi.org/10.2337/dc09-2191

[36] Yoon, N.M., Cavaghan, M.K., Brunelle, R.L. and Roach, P. (2009) Exenatide Added to Insulin Therapy: A Retrospective Review of Clinical Practice over Two Years in an Academic Endocrinology Outpatient Setting. Clinical Therapeutics, 31, 1511-1523. http://dx.doi.org/10.1016/j.clinthera.2009.07.021

[37] Sheffield, C.A., Kane, M.P., Busch, R.S., Bakst, G., Abelseth, J.M. and Hamilton, R.A. (2008) Safety and Efficacy of Exenatide in Combination with Insulin in Patients with Type 2 Diabetes Mellitus. Endocrine Practice, 14, 285-292. http://dx.doi.org/10.4158/EP.14.3.285

[38] Nayak, U.A., Govindan, J., Baskar, V., Kalupahana, D. and Singh, B.M. (2010) Exenatide Therapy in Insulin-Treated Type 2 Diabetes and Obesity. QJM, 103, 687-694. http://dx.doi.org/10.1093/qjmed/hcq112

[39] Nathan, D.M., Buse, J.B., Davidson, M.B., Heine, R.J., Holman, R.R., Sherwin, R., et al. (2006) Management of Hyperglycaemia in Type 2 Diabetes: A Consensus Algorithm for the Initiation and Adjustment of Therapy: A Consensus Statement from the American Diabetes Association and the European Association for the Study of Diabetes. Diabetes Care, 29, 1963-1972. http://dx.doi.org/10.2337/dc06-9912

[40] Schernthaner, G., Barnett, A.H., Betteridge, D.J., Carmena, R., Ceriello, A., Charbonnel, B., et al. (2010) Is the ADA/EASD Algorithm for the Management of Type 2 Diabetes (January 2009) Based on Evidence or Opinion? A Critical Analysis. Diabetologia, 53, 1258-1269. http://dx.doi.org/10.1007/s00125-010-1702-3 
[41] German Diabetes Association, Matthaei, S., Bierwirth, R., Fritsche, A., Gallwitz, B., Häring, H.U., et al. (2009) Medical Antihyperglycaemic Treatment of Type 2 Diabetes Mellitus: Update of the Evidence-Based Guideline of the German Diabetes Association. Experimental and Clinical Endocrinology \& Diabetes, 117, 522-557. http://dx.doi.org/10.1055/s-0029-1239559

[42] Apovian, C.M., Bergenstal, R.M., Cuddihy, R.M., Qu, Y., Lenox, S., Lewis, M.S., et al. (2010) Effects of Exenatide Combined with Lifestyle Modification in Patients with Type 2 Diabetes. American Journal of Medicine, 123, 468.e917.

[43] Robles, G.I. and Singh-Franco, D. (2009) A Review of Exenatide as Adjunctive Therapy in Patients with Type 2 Diabetes. Drug Design, Development and Therapy, 3, 219-240. http://dx.doi.org/10.2147/DDDT.S3321 